Dipublikasikan

Badan Pelaksana Kuliah Kerja Nyata

Universitas Lampung

Sekretariat Badan Pelaksana Kuliah Kerja Nyata, Universitas Lampung. Jl. Prof. Dr. Scemantri Brojonegoro No. 1, Bandar Lampung 35145.

\title{
PEMANFAATKAN MEDIA SOSIAL UNTUK PROMOSI PARIWISATA DAN POTENSI KEARIFAN LOKAL DI KELURAHAN BATU PUTUK, KECAMATAN TELUK BETUNG BARAT, KOTA BANDAR LAMPUNG
}

\author{
Aristoteles $^{1}$,Alya Samira Rahmaputri ${ }^{2}$, Anisa Raden ${ }^{3}$, Cahlia Kurnia ${ }^{4}$, Muhammad Fakhri \\ Robbani $^{5}$, Nitami Sari ${ }^{6}$, Noval Aditya Marlon ${ }^{7}$, Swarna Darma Utama ${ }^{8}$ \\ 1,3,7Program Studi Ilmu Komputer/Jurusan Ilmu Komputer/FMIPA, Universitas Lampung \\ ${ }^{2}$ Program Studi Teknik Sipil/Jurusan Teknik Sipil/FT, Universitas Lampung \\ ${ }^{4}$ Program Studi Fisika/Jurusan Fisika/FMIPA, Universitas Lampung \\ ${ }^{5}$ Program Studi Teknik Informasi/Jurusan Teknik Elektro/FT, Universitas Lampung \\ ${ }^{6}$ Program Studi Manajemen/Jurusan Menajemen/FEB, Universitas Lampung \\ ${ }^{8}$ Program Studi Teknik Kimia/Jurusan Teknik Kimia/FT, Universitas Lampung \\ Penulis Korespondensi: swarna.darma1041@students.unila.ac.id
}

\begin{abstract}
Abstrak
Pemanfaatan media sosial dalam era digital sangat memudahkan penyebaran informasi dan promosi dari berbagai sektor kehidupan. Media sosial yang berada di tengah masyarakat terbukti dapat mempromosikan pariwisata menjadi lebih iteraktif, informatif, dan juga fleksibel dalam penyampain informasi yang dapat menarik wisatawan. Akan tetapi, agar pemanfaatan media sosial dapat efektif dalam kegiatan promosi wisata perlu adanya strategi dan persiapan pembuatan konten yang dapat menarik wisawan datang dan melihat keunikan dari tempat wisata kita. Berdasarkan hal tersebut, tim KKN Desa Batu Putuk melakukan kegiatan dengan pemanfaatkan media sosial untuk promosi pariwisata dan potensi kearifan lokal di Kelurahan Batu Putuk
\end{abstract}

Kata kunci: Pariwisata, Kearifan Lokal, dan, Media Sosial

\begin{abstract}
The use of social media in the digital era greatly facilitates the dissemination of information and promotions from various sectors of life. Social media in the community is proven to be able to promote tourism to be more interactive and flexible in conveying information that can attract tourists. However, to become an effective social media in promotional activities, it is necessary to have a strategy and preparation of content creation that can attract tourists to come and see the uniqueness of our tourist attractions. Based on this, the KKN Batu Putuk Village team carried out activities by utilizing social media to promote tourism and the potential of local wisdom in Batu Putuk Village.
\end{abstract}

Keywords: Tourism, Local Wisdom, and, Social Media 


\section{Jurnal Pengabdian Kepada Masyarakat BUGUH}

Dipublikasikan

Badan Pelaksana Kuliah Kerja Nyata

Universitas Lampung

Sekretariat Badan Pelaksana Kuliah Kerja Nyata, Universitas Lampung.

Ji. Prof. Dr. Soemantri Brojonegoro No. 1, Bandar Lampung 35145.

\section{Pendahuluan}

Kelurahan Batu Putu, Kecamatan Teluk Betung Utara, Kota Bandar Lampung, memiliki topografi perbukitan dengan tanah yang subur, adanya aliran sungai, dan merupakan daerah penghasil buah-buahan. Kelurahan Batu Putu dikembangkan sebagai daerah pengembangan tujuan wisata kota dan memiliki potensi wisata unggulan seperti adanya wisata alam, yang menyajikan panorama alam yang indah. Terdapat beberapa objek wisata yang ada di Kelurahan Batu Putu di antaranya Air Terjun Batu Putu, Taman Wisata Wira Garden, Taman Bumi Kedaton, Taman Cibiah, dan sebagainya.

Untuk mendorong perkembangan sektor pariwisata perlu dilakukan promosi. Promosi pariwisata berkaitan dengan kegiatan komunikasi dan publikasi untuk membangun citra mengenai destinasi dan atraksi wisata (Risman, Wibhawa, \& Fedryansyah, 2016). Promosi adalah unsur dari bauran pemasaran organisasi yang bertujuan memberitahukan, membujuk, dan mengingatkan target pasar dari organisasi atau produk yang dipasarkan. Bentuk promosi yang mudah dan luas jangkauannya salah satunya adalah dengan menggunakan media sosial (Andhika, 2020).

Media sosial sangat berperan dalam penyebaran informasi bagi masyarakat luas. Jenis media sosial yang dikenal oleh masyarakat sangat beragam. Menurut hasil riset oleh 'We Are Social' diantara banyaknya jenis media sosial tersebut, media sosial yang diminati orang Indonesia saat ini diantaranya Youtube, Facebook, Instagram, dan Twitter (Larichy, 2020). Berdasarkan informasi yang dimuat dalam wartakota, Indonesia merupakan komunitas pengguna Instagram terbesar di Asia Pasifik dengan jumlah pengguna aktifnya mencapai 45 juta orang dari total pengguna global yang berjumlah 700 juta orang. Pengguna sosial media yang banyak ini dapat menjadi lahan untuk menaikkan profit dan memperlebar sayap bisnis sektor pariwisata (Asri, 2018).

Berangkat dari permasalahan yang ditemui di masyarakat, dimana hanya sebagian kecil masyarakat desa yang sadar akan potensi pariwisata yang ada di Kelurahan Batu Putuk, maka dilakukan kegiatan yang bertujuan untuk menambah pengetahuan bagi masyarakat desa mengenai dunia digital yang dapat meningkatkan minat masyarakat luas dan mampu mengembangkan potensi pariwisata tersebut, sehingga potensi wisata yang ada mampu memberi pengaruh positif terhadap potensi sektor lain yang juga ada di Kelurahan Batu Putuk (Wati, Haryono, \& Zulkarnain, 2019). Diharapkan pula pengenalan potensi wisata alam yang ada di Kelurahan Batu Putuk melalui sosial media kepada masyarakat luas dapat menjadikan Batu Putuk sebagai salah satu desa wisata yang terkenal dan mampu mendatangkan wisatawan baik dari dalam maupun luar daerah Lampung. (Puspitarini \& Nuraeni, 2019)

\section{Bahan dan Metode}

Metode dalam penulisan artikel ini menggunakan pendekatan kualitatif dengan menggunakan sosial media sebagai program kerja promosi wisata alam yang ada di Desa Batu Putuk selama pelaksanaan Kuliah Kerja Nyata sekaligus menjelaskan langkah-langkah dari pembuatan video, promosi video, hingga output dari program kerja tersebut (Kusuma, Hamdani, Nugraha, Nurhayati, \& Ramdhan, 2020). Terdapat 4 Wisata Alam yang dikunjungi selama pelaksanaan Kuliah Kerja Nyata yaitu Air Terjun Batu Putuk, Taman Wisata Wira Garden, Wisata Boemi Kedaton, dan Pesona Alam Cibiah. Data-data yang digunakan dalam pembuatan artikel ini bersumber dari pengalaman dan hasil observasi langsung oleh anggota kelompok. 


\section{Jurnal Pengabdian Kepada Masyarakat BUGUH}

Dipublikasikan

Badan Pelaksana Kuliah Kerja Nyata

Universitas Lampung

Sekretariat Badan Pelaksana Kuliah Kerja Nyata, Universitas Lampung.

Jl. Prof. Dr. Scemantri Brojonegoro No. 1, Bandar Lampung 35145.

Adapun langkah-langkah pembuatan video promosi wisata alam dalam program kerja ini antara lain:

1. Mengunjungi tempat Wisata Alam.

2. Merekam gambar setiap tempat yang menarik bagi pengunjung menggunakan kamera handphone.

3. Mengedit hasil rekaman video tersebut menggunakan aplikasi Flimorago yang terdapat di handphone.

4. Menambahkan suara yang bertujuan untuk menjelaskan tempat-tempat yang ada di Wisata Alam tersebut.

Tahapan-tahapan dalam melakukan promosi Wisata Alam yaitu dengan meng-upload video Wisata Alam ke sosial media seperti Youtube dan Instagram yang dimiliki oleh seluruh anggota kelompok.

Hasil dari kegiatan promosi tersebut dapat memungkinkan menarik minat para wisatawan atau masyarakat yang belum mengetahui keberadaan Wisata Alam tersebut untuk dapat berkunjung.

\section{Hasil dan Pembahasan}

\section{Hasil}

Program kerja pariwisata desa batu putuk ini berlangsung dari tanggal 14 agustus 2021 sampai dengan tanggal 05 september 2021. Program kerja ini dilaksanakan sebanyak empat kali yang terdiri dari pengambilan gambar dan video, editing video, dan promosi video melalui media sosial. Pada tannggal 13 agustus 2021 program ini dimulai dengan merencanakan alur atau konsep dalam pengambilan videonya. Lalu dilanjutkan dengan dengan editing video nya seperti ingin menggunakan backsound apa agar sesuai dengan suasananya, lalu pemilihan efek dan filter agar video tampak lebih baik. Selanjutnya melakukan promosi pada akun media sosial pribadi agar masyarakat luar daerah batu putuk dapat mengetahui wisata yang ada di desa batu putuk

Program kerja ini dimulai dengan mengunjungi wisata air terjun batu putuk pada tanggal 14 agustus 2021. Lalu kunjungan selanjutnya kami mengunjungi wisata alam wira garden pada tanggal 16 agustus 2021 Kemudian pada tanggal 24 agustus 2021 kami mengunjungi wisata boemi kedaton zoo. Selanjutnya yang terakhir pada tanggal 29 agustus kami mengunjungi wisata taman cibiah batu putuk. Selain melakukan pengambilan video pada wisata tersebut kami juga melakukan pengamatan terkait potensi apa saja yang dapat dikembangkan di wisata alam tersebut.

Setelah pengambilan video dan mengedit video, kami melakukan promosi melalui akun media sosial pribadi dengan tujuan agar masyarakat luar desa batu putuk dapat mengenal wisata yang ada pada desa batu putuk, sehingga nantinya akan mendapatkan keuntunggan dari setiap orang yang ingin berkunjung kesana. Berdasarkan pemantauan dan pengamatan kami selama berlangsungnya program kerja ini dapat disimpulkan bahwa pemanfaatan media sosial untuk promosi pariwisata dan potensi kearifan lokal di desa batu putuk dapat disimpulkan bahwa perhatian masyarakat luar desa batu putuk cukup tinggi. Hal ini dapat dilihat dari banyaknya pertanyaan dari masyarakat luar desa batu putuk mengenai pariwisata yang ada. Seperti contohnya yaitu: dimana letak lokasinya dan apakah perjalanan kesana dapat menggunakan kendaraan mobil?, fasilitas apa saja yang ada di dalam wisata tersebut?, apakah seluruh fasilitas dapat digunakan secara gratis? Dan masih banyak pertanyaan yang lainnya

Tabel 1 keadaan awal dan akhir yang diharapkan dari promosi melalui media sosial 


\section{Jurnal Pengabdian Kepada Masyarakat BUGUH}

Dipublikasikan

Badan Pelaksana Kuliah Kerja Nyata

Universitas Lampung

Sekretariat Badan Pelaksana Kuliah Kerja Nyata, Universitas Lampung. Ji. Prof. Dr. Scemantri Brojonegoro No. 1, Bandar Lampung 35145.

\begin{tabular}{|c|l|l|}
\hline \multicolumn{1}{|c|}{ Keadaan awal } & \multicolumn{1}{|c|}{ Perlakuan } & \multicolumn{1}{|c|}{ Keadaan akhir } \\
\hline $\begin{array}{l}\text { Masyarakat luar desa batu putuk } \\
\text { banyak yang belum mengetahui } \\
\text { terkait pariwisata dan kearifan lokal } \\
\text { apa saja yang ada di desa batu putuk }\end{array}$ & $\begin{array}{l}\text { Melakukan promosi melalui } \\
\text { media sosial agar lebih } \\
\text { tersebar informasi mengenai } \\
\text { pariwisata yang ada }\end{array}$ & $\begin{array}{l}\text { Masyarakat luar desa batu putuk } \\
\text { jadi mengetahui serta } \\
\text { meningkatnya jumlah peminat } \\
\text { pengujung ke pariwisata yang ada } \\
\text { di desa batu putuk }\end{array}$ \\
\hline
\end{tabular}

\section{Sumber: Hasil pengamatan dan diskusi tim KKN}

\section{Pembahasan}

Kegiatan wisata merupakan suatu kegiatan perjalanan baik yang dilakukan individu ataupun grup dari tempat tinggal menuju suatu tempat tertentu untuk mendapatkan pengalaman di luar aktivitas kesehariannya (seperti: bekerja, sekolah, mengurus rumah tangga, dll) dalam waktu yang sementara (Wicaksana \& Purwanto, 2014).

Kegiatan wisata dilakukan bukan di rumah atau hanya di kediaman si pelaku kegiatan melainkan di suatu tempat dengan tujuan tertentu, sehingga kegiatan tersebut memerlukan proses perjalanan, baik menggunakan transportasi darat, laut, ataupun udara (Sinulingga, Pardosi, Bangun, \& Siahaan, 2020). Kalau dilihat dari sisi ekonomi, kegiatan wisata merupakan kegiatan proses konsumsi terhadap suatu produk yang dilakukan oleh pelaku wisata dimulai dari tempat tinggalnya, diperjalanan dan ditempat tujuannya. Produk yang dikonsumsi tersebut merupakan suatu pengalaman total (total experiences) yang diperoleh oleh pelaku perjalanan wisata dalam proses konsumsinya tersebut. Sementara itu, terdapat tiga komponen penting yang membuat proses konsumsi terhadap suatu pengalaman berwisata itu terjadi, yaitu:

- Daya tarik wisata: segala sesuatu yang menarik dan menghasilkan pengalaman kepada pelaku perjalanan wisata, baik secara pasif maupun aktif, contoh: keindahan pantai, suasana pegunungan, gerhana, pentas seni, event olahraga, karnaval, menunggangi kuda, mendaki gunung, berselancar, bercengkrama dengan masyarakat, dll.

- Sarana penunjang wisata: segala sesuatu yang dapat memfasilitasi kegiatan wisata baik yang dapat diindera (tangible) maupun yang tidak dapat diindera (intangible), contoh: jasa transportasi, akomodasi, makan/minum, toilet, pramuwisata (guide), informasi dll.

- Infrastruktur/prasarana: segala sesuatu yang merupakan penunjang utama terselenggaranya proses kegiatan wisata dan kegiatan non wisata, contoh: jaringan jalan, bandara, terminal, pelabuhan, air bersih, listrik, telekomunikasi, dll (Susyanti \& Latianingsih, 2013).

Berdasarkan hasil survey dan pengamtan dengan melihat keunggulan potensi wisata yang dimiliki oleh Desa Batu Putuk serta melihat permasalahan yang terjadi di tengah masyarakat oleh karena itu, kami menyusun dan melaksanakan beberapa program kerja baik program kerja utama maupun tambahan. Dalam Program kerja kami yaitu pemanfaatan media sosial untuk promosi pariwisata dan potensi kearifan lokal di Kelurahan Batu Putuk, Kecamatan Teluk Betung Barat, Bandar lampung selanjutnya dari kami mahasiswa KKN UNILA melakukan dokumentasi dan mengambil data baik dari warga dan pengelola wisata tersebut berikut diantaranya adalah :

1. Air Terjun Batu Putuk merupakan objek wisata alam yang ada di desa Batu Putuk, wisata ini sudah memiliki beberapa fasilitas: seperti tempat parkir, kantin, mushola, tempat sampah, dan jalan yang

VOL 1 NO 42021 


\section{Jurnal Pengabdian Kepada Masyarakat BUGUH}

Dipublikasikan

Badan Pelaksana Kuliah Kerja Nyata

Universitas Lampung

Sekretariat Badan Pelaksana Kuliah Kerja Nyata, Universitas Lampung. Ji. Prof. Dr. Scemantri Brojonegoro No. 1, Bandar Lampung 35145.

memadai sehingga memudahkan para pengunjung untuk mencapai lokasi air terjun tersebut sehingga diharapkan para pengunjung sehingga diharapkan pengunjung menjadi nyaman namun ada beberapa masalah yaitu kurangnya kunjungan dari wisatawan sehingga setelah berkoordinasi dengan kelurahan kami pun memlakukan beberapa dokumentasi dan akan di promosikan sehingga diharapkan wisata air terjun batu putuk akan menjadi ramai kembali sehingga dapat memutar ekonomi warga.

2. Taman Pesona Alam Cibiah merupakan objek wisata alam yang ada di desa Batu Putuk, wisata ini berupa konsep taman dengan terdapat tempat photo seperti taman hias dan bonsai serta gazebo untuk tempat beristirahat dan juga ada rekreasi berupa kolam renang dari sumber mata air alami sehingga selain melihat keindahan taman juga dapat berenang selain itu ada beberapa fasilitas lainya seperti tempat parkir, kantin, mushola, tempat sampah, dan jalan yang memadai sehingga memudahkan para pengunjung untuk mencapai lokasi tersebut sehingga diharapkan para pengunjung sehingga diharapkan pengunjung menjadi nyaman namun ada beberapa masalah yaitu kurangnya kunjungan dari wisatawan sehingga setelah berkoordinasi dengan kelurahan kami pun memlakukan beberapa dokumentasi dan akan di promosikan sehingga diharapkan wisata air terjun batu putuk akan menjadi ramai kembali sehingga dapat memutar ekonomi warga.

3. Taman Wisata Wira Garden merupakan objek wisata alam yang ada di desa Batu Putuk, wisata ini berupa konsep taman dan juga tempat camping yang dimana bisa digunakan untuk acara besar seperti pernikahan atau acara menginap di alam dan juga terdapat tempat photo selain itu ada beberapa fasilitas lainya seperti tempat parkir, kantin, mushola, tempat sampah, dan jalan yang memadai sehingga memudahkan para pengunjung untuk mencapai lokasi air terjun tersebut sehingga diharapkan para pengunjung sehingga diharapkan pengunjung menjadi nyaman namun ada beberapa masalah yaitu kurangnya kunjungan dari wisatawan sehingga setelah berkoordinasi dengan kelurahan dan pengelola wisata kami pun memlakukan beberapa dokumentasi dan akan di promosikan sehingga diharapkan wisata air terjun batu putuk akan menjadi ramai kembali sehingga dapat memutar ekonomi warga.

4. Taman Wisata Bumi Kedaton merupakan objek wisata alam yang ada di desa Batu Putuk, wisata ini berupa konsep taman, tempat camping, temapt meeting untuk rapat, kebun binatang dan juga kolam renang bagi para pengunjung yang ingin menginap juga disediakan beberapa paviliun selain itu juga ada beberapa fasilitas lainya seperti tempat parkir, kantin, mushola, tempat sampah, dan jalan yang memadai sehingga memudahkan para pengunjung untuk mencapai lokasi air terjun tersebut sehingga diharapkan para pengunjung sehingga diharapkan pengunjung menjadi nyaman namun ada beberapa masalah yaitu kurangnya kunjungan dari wisatawan sehingga setelah berkoordinasi dengan kelurahan kami pun memlakukan beberapa dokumentasi dan akan di promosikan sehingga diharapkan wisata air terjun batu putuk akan menjadi ramai kembali sehingga dapat memutar ekonomi warga. 
Dipublikasikan

Badan Pelaksana Kuliah Kerja Nyata

Universitas Lampung

Sekretariat Badan Pelaksana Kuliah Kerja Nyata, Universitas Lampung.

Jl. Prof. Dr. Soemantri Brojonegoro No. 1, Bandar Lampung 35145.

\section{Faktor Pendukung dan Faktor Penghambat}

\section{1) Faktor Pendukung}

Adapun faktor-faktor yang mendukung demi kelancaran dan keberhasilan program kerja ini adalah:

a) Adanya kerjasama yang baik diantara pihak pengelola tempat dan anggota tim, mulai dari perencanaan hingga pelaksanaan kegiatan ini.

b) Keindahan alam dan kearifan lokal yang dimiliki daerah masih dapat diolah dengan semaksimal mungkin.

c) Keramahan dan keterbukaan pihak pengelola, aparatur kelurahan, dan warga setempat pada kegiatan promosi pariwisata yang ada.

d) Cukup memadainya sarana dan prasarana berupa alat dan bahan kegiatan berupa laptop, hp, dan kendaraan.

\section{2) Faktor Penghambat}

Masih sedikitnya wisatawan yang berkunjung dan tempat wisata yang tidak terpelihara. Hal ini dikarenakan tidak diperbolehkan berkerumunan atau kumpul di satu tempat dengan banyak peserta karena dikhawatirkan dapat meningkatkan penyebaran COVID-19. Sehingga mengurangkan pendapatan tempat wisata untuk membangun dan mengolah tempat wisatanya Kembali.

\section{Kesimpulan dan Saran}

Berdasarkan hasil pembahasan dari kegiatan yang telah dilakukan dapat disimpulkan bahwa :

1) Dengan memanfaatkan media sosial dan pemberhentian Pemberlakuan Pembatasan Kegiatan Masyarakat (PPKM) terjadi peningkatan pada beberapa tempat wisata yang ada di Kelurahan Batu Putuk.

2) Meningkatnya pemahaman masyarakat terhadap kearifan lokal yang dimiliki Kelurahan Batu Putuk

3) Masyarakat mulai mempunyai sikap peduli lingkungan untuk menjaga keindahan alam yang ada di Kelurahan Batu Putuk

4) Telah terbuat dan terpublikasinya video promosi untuk peningkatan daya tarik wisatawan untuk berkunjung.

\section{Saran}

Berdasarkan kesimpulan di atas dapat disarankan :

1) Untuk Peneliti Selanjutnya

Penyebarluaskan video promosi dengan bekerja sama dengan organisasi yang sedang membuka paid promote.

2) Untuk Pengelola Tempat Wisata

Pengelola tempat wisata dapat melakukan percepatan perbaikan agar wisatawan menjadi lebih nyaman. 


\section{Jurnal Pengabdian Kepada Masyarakat BUGUH}

Dipublikasikan

Badan Pelaksana Kuliah Kerja Nyata

Universitas Lampung

Sekretariat Badan Pelaksana Kuliah Kerja Nyata, Universitas Lampung.

Ji. Prof. Dr. Scemantri Brojonegoro No. 1, Bandar Lampung 35145.

\section{Ucapan Terima Kasih}

Puji syukur kepada Allah SWT yang senantiasa kami panjatkan karena hanya dengan rahmat dan hidayahNya kami dapat menyelesaikan pengabdian ini. Kami juga banyak mendapatkan dukungan dari berbagai pihak yang telah menyumbangkan pikiran, waktu, tenaga, dan sebagainya. Oleh karena itu, pada kesempatan yang baik ini kami mengucapkan terima kasih kepada:

a) Universitas Lampung

b) BPKKN Universitas Lampung

c) Dosen KDPL Mahasiswa Universitas Lampung

d) Dosen DPL Mahasiswa Universitas Lampung

e) Kepala Desa Gedung Harapan Kec. Jati Agung Lampung Selatan

f) Masyarakat Desa Gedung Harapan Kec. Jati Agung Lampung Selatan

Semoga amal dan kebaikan yang diberikan kepada kami akan mendapatkan balasan dari Allah SWT. Aamiin.

\section{Daftar Pustaka}

Andhika, A. (2020). Penggunaan Video Promosi Wisata Melalui Youtube untuk Meningkatkan Daya Tarik Wisatawan ke Provinsi Kalimantan Selatan. Jurnal Mutakallimin: Jurnal Ilmu Komunikasi, 2(2), 26-30.

Asri, N. (2018). Pelatihan Pemanfaatan Media Sosial Untuk Promosi Pariwisata dan Potensi Kearifan Lokal di Pantai Sayang Heualang Kab. Garut. Jurnal Pengabdian Kepada Masyarakat, 2(12), 1-4.

Kusuma, S. S., Hamdani, D., Nugraha, D., Nurhayati, Y., \& Ramdhan, R. F. (2020). Pendampingan dan Pembuatan Video Profile untuk Promosi Wisata Desa Cisantana Kabupaten Kuningan. Jurnal Pengabdian Masyarakat, 3(02), 81-88.

Larichy, R. (2020). Perancangan Video Promosi Desa Wisata Conto sebagai Upaya Meningkatkan Jumlah Kunjungan Wisatawan. Surabaya: Universitas Dinamika.

Puspitarini, D. S., \& Nuraeni, R. (2019). Pemanfaatan Media Sosial Sebagai Media Promosi (Studi Deskriptif pada Happy Go Lucky House). Jurnal Common, 3(1), 71-80.

Risman, A., Wibhawa, B., \& Fedryansyah, M. (2016). Kontribusi Pariwisata Terhadap Peningkatan Kesejahteraan Masyarakat Indonesia. Prosiding Penelitian \& Pengabdian Kepada Masyarakat, 3(1), 29-37.

Sinulingga, S., Pardosi, J., Bangun, N. C., \& Siahaan, H. (2020). Pembuatan Film Wisata Sebagai Media Promosi Parawisata di Desa Rumah Galuh Kabupaten Langkat. Jurnal Master Parawisata, 6(2), 350-375.

Susyanti, D. W., \& Latianingsih, N. (2013, Juni). Potensi Desa Melalui Pariwisata Pedesaan. Jurnal Ekonomi dan Bisnis, 12(1), 33-36. 


\section{BUGUH}

Dipublikasikan

Badan Pelaksana Kuliah Kerja Nyata

Universitas Lampung

Sekretariat Badan Pelaksana Kuliah Kerja Nyata, Universitas Lampung. Jl. Prof. Dr. Scemantri Brojonegoro No. 1, Bandar Lampung 35145.

Wati, W., Haryono, E., \& Zulkarnain. (2019). Studi Menurunnya Jumlah Wisatawan Yang Berkunjung di Taman Bumi Kedaton Bandar Lampung Tahun 2011. Jurnal Penelitian Geografi, 2(2), 270-283.

Wicaksana, R. B., \& Purwanto, A. (2014). Pembuatan Video Profil Tempat Wisata Unggulan Di Klaten Sebagai Media Promosi. Data Manajemen dan Teknologi Informasi, 14(04), 37-39. 